\title{
Corpus Callosum Volume and Interhemispheric Transfer in Multiple Sclerosis
}

\author{
L.N. Brown, Y. Zhang, J.R. Mitchell, R. Zabad, L.M. Metz.
}

\begin{abstract}
Background: The corpus callosum (CC) is frequently compromised in patients with multiple sclerosis (MS). Structural and functional measurements of the CC may be useful to monitor the progression of the disease. The aim of this pilot study was to determine if bimanual tactile temporal thresholds correlates with $\mathrm{CC}$ volume. A tactile temporal threshold is the longest temporal interval that separates the onsets of two tactile stimuli when they are judged by the observer as simultaneous. Judgments to bimanual stimulations require interhemispheric transfer via the CC. Methods: Thresholds were examined in MS patients and matched controls. Magnetic resonance (MR) images were acquired on a 3T MR system within 48 hours of clinical assessment and measurement of thresholds. Results: Corpus callosum volume was assessed by using a semiautomatic livewire algorithm. The CC volume was smaller (by $21 \%$ on average, $\mathrm{p}<0.01$ ) and thresholds were higher (by $49 \%$ on average, $\mathrm{p}<0.03$ ) in MS patients when compared to controls. A significant correlation $(\mathrm{r}=-0.66, \mathrm{p}=0.01)$ between $\mathrm{CC}$ volume and thresholds emerged for the MS patients. Conclusion: Measuring treatment benefits of neuroprotective and repair therapies is a well recognized challenge in MS research. The overall findings of this study suggest that these measurements, which involve the transfer of information interhemispherically via the CC, may be promising outcome measures that warrant further scientific exploration to develop a model to measure recovery.
\end{abstract}

RÉSUMÉ: Volume du corps calleux et transfert interhémisphérique dans la sclérose en plaques. Contexte : Le corps calleux (CC) est souvent impliqué dans le processus pathologique chez les patients atteints de sclérose en plaques (SP). Des mesures structurales et fonctionnelles du CC peuvent être utiles pour surveiller la progression de la maladie. Objectif : Le but de cette étude exploratoire était de déterminer si les seuils temporaux de discrimination tactile bimanuelle sont corrélés au volume du CC. Un seuil temporel de discrimination tactile est l'intervalle le plus long qui sépare le début de deux stimuli tactiles quand ils sont jugés par l'observateur comme étant simultanés. Les évaluations des stimulations bimanuelles requièrent un transfert interhémisphérique via le CC. Méthodes : Les seuils de discrimination tactile ont été examinés chez des patients atteints de SP et des témoins appariés. Une évaluation par IRM a été effectuée au moyen d'un système IRM 3T dans les 48 heures de l'évaluation clinique et de la mesure des seuils. Résultats : Le volume du CC a été évalué au moyen d'un algorithme pour vidéo semi-automatisé "livewire". Le volume du CC était plus petit (de $21 \%$ en moyenne ; p < 0,01) et les seuils étaient plus élevés (de $49 \%$ en moyenne ; p < 0,03) chez les patients atteints de SP par rapport aux témoins. Il existait une corrélation significative $(r=-0,66 ; p=0,01)$ entre le volume du CC et les seuils chez les patients atteints de SP. Conclusion : La mesure des bénéfices du traitement neuroprotecteur et réparateur est un défi bien connu en recherche sur la SP. Les observations faites au cours de cette étude suggèrent que ces mesures, qui comportent le transfert interhémisphérique d'information via le CC, pourraient aider à l'évaluation des résultats d'un traitement. Ceci méritent une exploration scientifique plus poussée afin de développer un modèle pour évaluer la récupération.

Can. J. Neurol. Sci. 2010; 37: 615-619

The largest and most important commissure for transferring information inter-hemispherically is the corpus callosum (CC); a white matter structure connecting homologous regions of the two cerebral hemispheres. The $\mathrm{CC}$ is an important structure for higher-order activities that typically involve the transfer of information between cerebral hemispheres. It is known that there is an advantage to integrate incoming information efficiently between the hemispheres for demanding or complex tasks (e.g., driving a vehicle). Thus, damage to the white matter of the $\mathrm{CC}$, which is a frequent occurrence in multiple sclerosis (MS), will likely compromise transcallosal conduction time. Prolonged neural conduction time not only results in slower speed of information processing, but slower processing speed has a negative impact on cognitive processes, including psychomotor speed and accuracy ${ }^{1}$.
This pilot study examines a structural measure (magnetic resonance imaging; MRI) and a functional measure (tactile temporal thresholds; TTTs) of the CC in patients with MS. The research investigating the relationship between $\mathrm{CC}$ damage or atrophy and interhemispheric transfer efficiency in MS patients is essentially in its infancy. The number of studies investigating

From the Department of Clinical Neurosciences (LNB, YZ, JRM, LMM), Diagnostic Imaging (JRM), University of Calgary, Calgary, Alberta, Canada; Department of Neurological Sciences (RZ), University of Nebraska Medical Centre, Omaha, Nebraska, USA.

Received December 11, 2009. Final Revisions Submitted April 13, 2010. Correspondence to: Lenora N. Brown, Department of Clinical Neurosciences, Foothills Medical Centre, 1104, 1403-29 Street NW, Calgary, Alberta, T2N 2T9, Canada. 
the potential effects of $\mathrm{CC}$ degeneration in MS patients (i.e., interhemispheric dysfunction, cognitive impairment) has been slowly increasing over the past several years.

Magnetic resonance imagining studies have shown that callosal lesions, axonal damage within the $\mathrm{CC}$, and loss of $\mathrm{CC}$ volume are frequently observed in MS patients ${ }^{2-10}$. In fact, a quantitative pathological study demonstrated a reduction of more than $50 \%$ in the number of axons passing through the $\mathrm{CC}$ when the brains of deceased secondary progressive MS (SPMS) patients (mean disease duration of 21 years) were compared to age-and-sex matched controls who died from non-neurological conditions $^{5}$. With respect to longitudinal data, the results of a nine-year longitudinal MRI study showed a CC atrophy rate of $9.25 \mathrm{~mm}^{2}$ annually for all MS disease courses that was unrelated to age ${ }^{9}$. A five-year longitudinal MRI study demonstrated both callosal atrophy and impaired interhemispheric transfer in a group of early stage clinically definite relapsing-remitting MS (RRMS) patients ${ }^{11}$. Although it is not surprising that interhemispheric transfer dysfunction in MS has been documented ${ }^{2,11-22}$, few studies have correlated the severity of CC atrophy with interhemispheric transfer measures in MS patients ${ }^{11,18}$. The overall findings of these few studies suggest that $\mathrm{CC}$ degeneration will occur in a large proportion of patients with MS and that measurements of CC atrophy, and/or functional measures of CC integrity, may be sensitive markers of MS progression regardless of the stage or course of disease.

The aim of this study is to determine whether bimanual tactile temporal thresholds, which rely on interhemispheric transfer, correlate with MS-related CC atrophy as measured by CC volume on MRI. Tactile temporal thresholds represent the time interval between the onset of two tactile stimuli when they are judged to be simultaneous. The findings of our previous work have shown that (i) MS patients have significantly prolonged TTTs when compared to matched controls ${ }^{13}$, (ii) these thresholds have excellent test-retest reliability ${ }^{23}$, and (iii) there is no or minimal learning or practice effects ${ }^{23}$. Preliminary data have indicated that TTTs may be associated with relapses and recovery ${ }^{24}$. To date, the results suggest that TTTs are reliable measures of central nervous system integrity, which demonstrate promise as an outcome measure in MS.

In this study, we hypothesized that the MS group will have significantly less CC volume and prolonged TTTs when compared to a normal control group. We also hypothesized that TTTs would inversely correlate with $\mathrm{CC}$ volume since the efficiency of interhemispheric transfer times will likely be lengthened by the loss/damage of the axons in the CC of MS patients.

\section{Methods}

\section{Participants}

A total of 13 MS patients (3 males and 10 females) and 11 controls (1 male and 10 females) were tested. Patients were diagnosed by a neurologist as defined by standard clinical and neuroimaging criteria ${ }^{25}$ at a Canadian MS clinic. There were ten patients with RRMS, two patients with SPMS, and one with primary progressive MS (PPMS). The age of the MS patients ranged from 28 to 57 years (Mean $[\mathrm{M}]=43.77$, standard deviation $[S D]=10.14)$, while the age for the controls ranged from 25 to 54 years $(M=40.18, S D=10.91)$. The Kurtzke
Expanded Disability Status Scale (EDSS) ${ }^{26}$ was employed to quantify disability (i.e., 1.0 - $4.5=$ ambulatory without aid; 5.0 impairment in ambulation). The EDSS ranged from 1.5 to 7.50 $(\mathrm{M}=3.73, \mathrm{SD}=1.76)$. The duration from the time of a MS diagnosis ranged from 5 to 288 months $(\mathrm{M}=91.23, \mathrm{SD}=80.83)$.

Exclusion criteria included substance abuse, use of sedating medications, psychiatric illness, and occurrence of an MS exacerbation within the previous 30 days. Control participants consisted of staff members (i.e., nurses), and family members or friends of the patients. Control participants were excluded if they had ever been under a doctor's care for a neurological or psychiatric illness. All participants were recruited at a local MS clinic. The study was approved by the local Institutional Review Board in accordance to the ethical standards of the 1964 Declaration of Helsinki. Informed consent was obtained by all participants prior to imaging and testing.

All participants underwent a MRI and tactile testing within a 48 hour period. Multiple sclerosis patients also underwent a neurological examination by a neurologist within the 48 hours.

\section{Neuroimaging}

All of the participants were imaged on a 3T MR Scanner (GE Healthcare, Waukesha, WI). A set of sagittal T1-weighted MR images was acquired using a spin-echo pulse sequence $(\mathrm{TR} / \mathrm{TE}=$ $53 / 2 \mathrm{~ms}$, slice thickness $=5 \mathrm{~mm})$. The $\mathrm{CC}$ volume $\left(\mathrm{mm}^{3}\right)$ was measured by an experienced neuroradiologist on a mid-sagittal slice using a liveWire program implemented in 3D Slicer (Brigham and Women's Hospital, Harvard Medical School) (Figure 1). The liveWire is an intelligent algorithm that finds the best-fit contour of an image structure based on the user-selected seed points on the image. In this study, the CC volume was automatically calculated from the 3D Slicer by multiplying the area (contour) of the CC with the MRI slice thickness. This semiautomatic method therefore allows an optimal assessment of irregular structures such as the $\mathrm{CC}$ and reduces measurement error when compared to manual assessment. Evidence demonstrates that the variability of the liveWire program in cartilage thickness measurement was $3 \%{ }^{27}$.

\section{Tactile Apparatus}

A mechanical stimulator was used to deliver the tactile stimuli to the index fingers. The stimulator consisted of enclosed solenoids that were attached to the base of a thin rod. When the solenoid was charged, a thin rod was thrust upwards through a central core of a cylinder to where the palmar surface of the finger-to-be-stimulated rested. The top surface of each cylinder had a concave surface for resting index fingertips. The stimulator was aligned $90^{\circ}$ outwards from the body midline. The rods were matched in regard to vertical extension (0.05 milliseconds [ms]) skin depression (1 millimetres [mm]) and plateau duration (9.95 $\mathrm{ms}$ ). Foam padding surrounded the stimulators to rest elbows and forearms in order to minimize any vibrations that may have occurred during stimulus delivery. Specific details about the tactile stimulator, software, and task procedures have been published ${ }^{13}$.

\section{Parameter Estimation Procedures}

A modified version of the Parameter Estimation by Sequential Testing (PEST) algorithm which allows the value of 


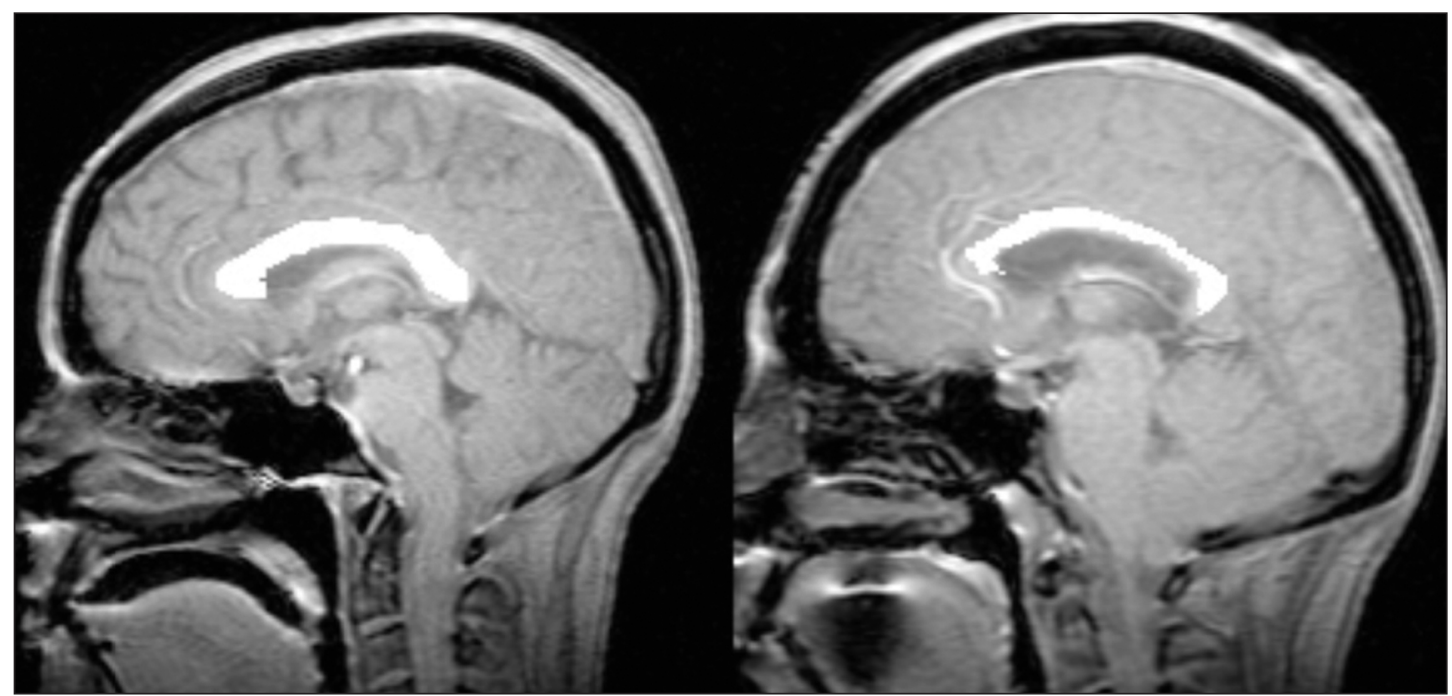

Figure 1: Midsagittal T1-weighted images displaying measurements of the corpus callosum (CC) (masked as white) using the liveWire algorithm. The CC volume of a control subject (left) is larger than that of a MS patient (right).

thresholds to be determined in as few trials as possible, was used to determine the TTTs. Using a binary forced-choice (YES/NO) paradigm, the interval between the onset of the first stimulus to the onset of the second stimulus (Stimulus Onset Asynchrony; SOA) was adjusted according to the participant's previous response. Participants responded "YES" when they perceived the onset of the stimulus pairs as simultaneous, or "NO" when they perceived the onset of the stimuli pairs as non-simultaneous. The SOA step size decreased by a constant value in association to "NO" responses (non-simultaneity perceived), and the SOA step size would increase by half of the previous SOA value in association to "YES" responses (simultaneity perceived). The program terminated when the SOA step size reached 1 millisecond. The initial SOA step size was set at $10 \mathrm{~ms}$, while the termination step size was set 1 millisecond. The temporal threshold was the SOA value upon termination for each sequence.

\section{Tactile Measurement}

In order to ensure that each participant perceived the sensory stimuli, each participant received a tactile screening test in which participants were required to correctly identify the finger that was stimulated and achieve 100\% accuracy for 20 trials (i.e., fingers were labeled with numbers for identification).

Each participant received a practice block and five test blocks of trials. The practice block provided a starting SOA value for the test blocks for each participant. Index fingers rested on the fingertip holders in order to cover the tiny hole for the thin rod to thrust upwards for stimulation. Bimanual presentations require interhemispheric transfer because the information that each cerebral hemisphere receives from the contralateral hemispace needs to be integrated so that a comparison of the two stimuli can be made. Verbal responses were entered into the computer, which triggered the delivery of the next pair of tactile stimuli.
Individual mean tactile temporal thresholds, as measured in $\mathrm{ms}$, were calculated for each participant across the five blocks of trials. Corpus callosum volume was measured in $\mathrm{mm}$. We used a one-way analysis of variance (ANOVA) to establish group differences. A p-value less than, or equal to, 0.05 was established to indicate statistically significant differences.

\section{RESULTS}

There were no group differences for age, $\mathrm{F}(1,22)=.69, p=$ .417. A one-way ANOVA revealed group differences for $\mathrm{CC}$ volume, $\mathrm{F}(1,22)=8.47, p=.008$. The $\mathrm{CC}$ volume was approximately $21 \%$ smaller for the MS group $(\mathrm{M}=3.00, \mathrm{SD}=$ $.58)$ when compared to the controls $(\mathrm{M}=3.67, \mathrm{SD}=.54)$. A separate one-way ANOVA revealed that MS patients had significantly higher thresholds than controls, $\mathrm{F}(1,22)=5.03, \mathrm{p}=$ .035 . The average TTT for the MS group $(\mathrm{M}=79.62, \mathrm{SD}=$ $34.13)$ was approximately $49 \%$ higher than the controls $(\mathrm{M}=$ $53.16, \mathrm{SD}=20.64)$. Figure 2 displays the means and standard errors for TTTs and CC volume by group.

A post-hoc correlational analysis for the MS group was conducted to determine the relationships between bimanual TTTs, CC volume, EDSS, and duration of disease. A significant inverse correlation between $\mathrm{CC}$ volume and TTTs was revealed ( $\mathrm{r}=-.661, p=.014)$. Expanded disability status scale was positively significantly correlated with TTTs $(r=.606, \mathrm{p}=.028)$, and significantly negatively correlated with $\mathrm{CC}$ volume $(\mathrm{r}=$ $.669, p=.012)$. No other significant correlations emerged. Given that the etiology for RRMS and SPMS differ from PPMS, a second correlation analysis was undertaken after removing the data of the one PPMS patient. This particular patient also had an EDSS of 7.5, which was the highest score in the sample. The results of this analysis did not differ such that a significant inverse correlation between TTTs and CC volume was again found $(\mathrm{r}=-.642, \mathrm{p}=.024)$. There were no significant correlations 


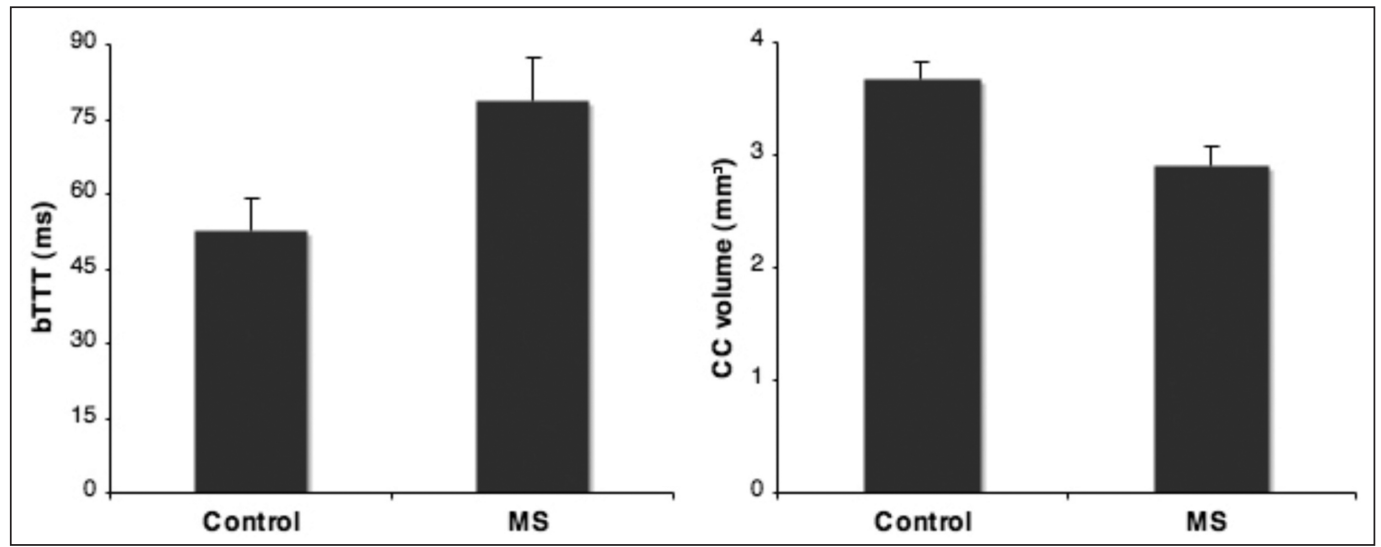

Figure 2: The left graph displays the mean tactile temporal thresholds with Standard Errors for the MS and control group; while the right graph displays the mean CC volume with Standard Errors as a function of group.

between $\mathrm{CC}$ volume and bimanual TTTs in the correlation analysis for the control group $(r=.044, p=.897)$. Age did not correlate with CC volume or bimanual TTTs for either group. Figure 3 displays the correlations as a function of group.

\section{DISCUSSION}

The aim of this pilot study was to determine whether bimanual TTTs, a functional measure of CC integrity, correlate with MRI measurements of CC volume in MS patients. Given that CC atrophy occurs frequently in MS patients, it was hypothesized that somatosensory measurements of interhemispheric transfer integrity would correlate with structural measures of $\mathrm{CC}$ volume in $\mathrm{MS}$ patients. The results demonstrated that MS patients have reduced CC volume when compared to controls and that interhemispheric transfer in MS patients is compromised. Overall, these findings are congruent with other findings that have reported $\mathrm{CC}$ damage, including degeneration, in MS patients ${ }^{2-5,7-10}$, and other reports of MSrelated dysfunction in interhemispheric transfer ${ }^{2,11-22}$. More importantly the data analysis for the MS group revealed a significant inverse relationship between CC volume and TTTs. This supports the hypothesis that degeneration of the CC affects the proficiency of the transfer of information interhemispherically. The correlation between CC volume, TTTs and EDSS scores emphasizes a possible relationship between the structural and functional integrity of the $\mathrm{CC}$ with disability. The lack of correlation between CC volume and bimanual TTTs in the control group would suggest that such relationships are only present in the case of impairment. Alternatively, the lack of correlation could be due to lack of variability within the control group.

Pelletier and colleagues ${ }^{11}$ employed a bilateral finger localization sensory task (i.e., a spatial task relative to temporal) and reported a significant correlation between global callosal measures and sensory performance. Collectively, the findings of these studies suggest that functional measures of the callosal transfer may be useful outcome measures in MS.

Limitations of this study include a small sample size and the large range of disability as measured by EDSS. Nonetheless, the results of this study indicate that further research may prove

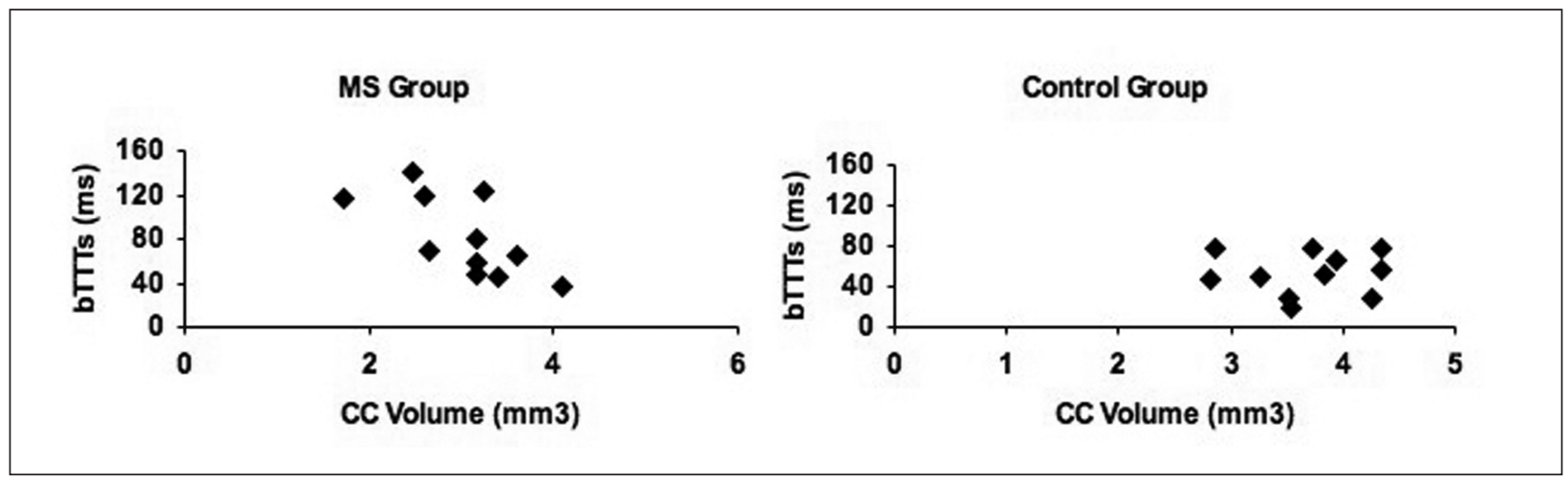

Figure 3: The left graph displays the correlation between CC volume and TTTs for the MS Group; while the right graph displays no correlation between CC volume and TTTs for the control group. 
promising in the identification of simple functional measures of $\mathrm{CC}$ integrity. These findings indicate that structural and functional measures of $\mathrm{CC}$ integrity may be useful clinical outcome measures in MS, including the measurement of treatment benefits of neuroprotective and repair therapies, which is currently a well recognized challenge in MS research. An important aspect of this potential outcome measure is that the measurement of TTTs is non-invasive, inexpensive, portable, convenient to administer, and does not fatigue or upset the subjects. Although the small sample size in this study limits broad conclusions, our results indicate that further scientific investigation correlating functional and structural measures of the $\mathrm{CC}$ is warranted.

\section{Conclusions}

As a preliminary study, the $\mathrm{CC}$ volume was analyzed as an entire structure. Future investigations should include additional measures $\mathrm{CC}$ integrity at different regions. Although interhemispheric transfer of somatosensory information relies on posterior mid-body CC integrity, measurements of the transfer of visual information (splenium section), and motor coordination information (anterior mid-body portion of the CC) may contribute to the development of a CC model. In addition, further exploration of the relationships between the structural and functional aspects of the $\mathrm{CC}$ in a larger sample for replication purposes would be useful, with the inclusion of factors such as disability, MS course, and demographic information such as education. Finally, employment of neuropsychological tests would be useful to determine the relationship between interhemispheric transfer dysfunction and various aspects of cognitive impairment.

\section{ACKNOWLEDGEMENTS}

The authors thank Catherine Riddell for her dedication in the recruitment and testing of patients with multiple sclerosis. This research was supported by the Multiple Sclerosis Society of Canada.

\section{REFERENCES}

1. Lazeron RHC, De Sonneville LMJ, Scheltens P, Polman CH, Barkhof F. Cognitive slowing in multiple sclerosis is strongly associated with brain volume reduction. Mult Scler. 2006;12: 760-8.

2. Barkhof F, Elton M, Lindeboom J, Tas MW, Schmidt WF, Hommes $\mathrm{OR}$, et al. Functional correlates of callosal atrophy in relapsingremitting multiple sclerosis patients. A preliminary MRI study. $\mathbf{J}$ Neurol. 1998;245:153-8.

3. Barnard RO, Triggs M. Corpus callosum in multiple sclerosis. J Neurol Neurosurg Psychiatry. 1974;37:1259-64.

4. Dietemann JL, Beigelman S, Rumbach L, Vouge M, Tajamady T, Faubert C, et al. Multiple sclerosis and corpus callosum atrophy: relationship of MRI findings to clinical data. Neuroradol. 1988; 30:478-80.

5. Evangelou N, Esiri M, Smith S, Palace J, Matthews PM. Quantitative pathological evidence for axonal loss in normal appearing white matter in multiple sclerosis. Ann Neurol. 2000; 47:391-5.

6. Figueira F, Santos VS, Figueira G, Silva ACM. Corpus callosum index: a practical method for long-term follow-up in multiple sclerosis. Arq Neuropsiquiatr. 2007;65:931-5.

7. Gean-Marton AD, Vezina LG, Marton KI, Stimac GK, Peyster RG, Taveras JM, et al. Abnormal corpus callosum: a sensitive and specific indicator of multiple sclerosis. Neuroradiol. 1991;180: 215-21.

8. Joonmi OH, Pelletier D, Nelson SJ. Corpus callosum axonal injury in multiple sclerosis measured by proton magnetic resonance spectroscopic imaging. Arch Neurol. 2004;61:1081-6.

9. Martola J, Stawiarz L, Fredikson S, Hillert J, Bergström J, Flodmark $\mathrm{O}$, et al. Progression of non-age-related callosal brain atrophy in multiple sclerosis: a 9-year longitudinal MRI study representing four decades of disease development. J Neurol Neurosurg Psychiatry. 2007;78:375-80.

10. Simon JH, Holtäs SL, Schiffer RB, Rudick RA, Herndon RM, Kido DK, et al. Corpus callosum and subcallosal periventricular lesions in multiple sclerosis: Detection with MR Radiol. 1986; 160:363-7.

11. Pelletier J, Suchet L, Witjas T, Habib M, Guttmann CRG, Salamon $\mathrm{G}$, et al. A longitudinal study of callosal atrophy and interhemispheric dysfunction in relapsing-remitting multiple sclerosis. Arch Neurol. 2001;58:105-11.

12. Boroojerdi B, Hungs M, Mull M, Töpper R, Noth J. Interhemispheric inhibition in patients with multiple sclerosis. Electroencephalogr Clin Neurophysiol. 1998;109:230-7.

13. Brown LN, Metz LM, Sainsbury RS. Sensory temporal thresholds and interhemispheric transfer times in multiple sclerosis: a preliminary study of a new outcome measure. J Clin Exp Neuropsych. 2003;25:783-92.

14. Höppner J, Kunesch E, Buchmann J, Hess A, Großmann A, Benecke $\mathrm{R}$. Demyelination and axonal degeneration in corpus callosum assessed by analysis of transcallosally mediated inhibition in multiple sclerosis. Clin Neurophysiol. 1999;110:748-56.

15. Larson EB, Burnison DS, Brown WS. Callosal function in multiple sclerosis: Bimanual motor coordination. Cortex. 2002;38: 201-14.

16. Manson SC, Palace J, Frank JA, Matthews PM. Loss of interhemispheric inhibition in patients with multiple sclerosis is related to corpus callosum atrophy. Exp Brain Res. 2006;174: 728-33.

17. Pelletier J, Habib M, Lyon-Caen O, Salamon G, Poncet M, Khalil R. Functional and magnetic resonance imaging correlates of callosal involvement in multiple sclerosis. Arch Neurol. 1993; 50:1077-82.

18. Rao SM, Bernardin L, Leo GJ, Ellington L, Ryan SB, Burg LS. Cerebral disconnection in multiple sclerosis: relationship to atrophy of the corpus callosum. Arch Neurol. 1989;46:918-20.

19. Schmierer K, Niehaus L, Röricht S, Meyer B-U. Conduction deficits of callosal fibers in early multiple sclerosis. J Neurol Neurosurg Psychiatry. 2000;68:633-8.

20. Schnider A, Benson DF, Rosner LJ. Callosal disconnection in multiple sclerosis. Neurology. 1993;43:1243-5.

21. Warlop NP, Achten E, Debruyne J, Vingerhoets G. Diffusion weighted callosal integrity reflects interhemispheric communication efficiency in multiple sclerosis. Neuropsychologia. 2008;46:2258-64.

22. Wishart HA, Strauss E, Hunter M, Moll A. Interhemispheric transfer in multiple sclerosis. J Clin Exp Neuropsychol. 1995;17:937-40.

23. Brown LN, Metz LM, Eliasziw M. Identifying reliable change in tactile temporal thresholds in multiple sclerosis: test-retest reliability. Mult Scler. 2006;12:573-7.

24. Brown LN, Metz LM. Tactile temporal thresholds measure relapserelated change in multiple sclerosis: a preliminary study. Mult Scler. 2005;11:725-7.

25. McDonald WI, Comptson A, Edan G and the International Panel Recommended diagnostic criteria for multiple sclerosis: guidelines from the International Panel on the Diagnosis of Multiple Sclerosis. Ann Neurol. 2001;50:121-7.

26. Kurtzke JF. Rating neurologic impairment in multiple sclerosis: an expanded disability status scale (EDSS). Ann Neurol. 1983;13: 227-31.

27. Bowers ME, Trinh N, Tung GA, Crisco JJ, Kimia BB, Fleming BC. Quantitative MR imaging using "LiveWire" to measure tibiofemoral articular cartilage thickness. Osteoarthritis Cartilage. 2008;16(10):1167-73. 